\title{
Vitamin-D and Dexamethasone Stimulation of Estrogen Receptor-A and Androgen Receptor in Osteoblasts of Aggressive Periodontitis
}

\author{
Dahlia Herawati \\ Department of Periodontic Faculty of Dentistry, Universitas Gadjah Mada, Jl Denta Sekip Utara, \\ Yogyakarta 55281, Indonesia \\ Email: heradahlia@ugm.ac.id
}

\begin{abstract}
The objective of this study is to investigate the expression of estrogen receptor $\alpha$ and androgen receptor in osteoblasts derived from patients with aggressive periodontitis following stimulation using vitamin D and dexamethasone. Sample pieces of alveolar bone were collected from patients with aggressive periodontitis (PA) and from non-periodontitis subjects (NP), for both of which the patient's consent had been obtained. Osteoblasts were isolated from bone fragments by the explant method, stimulated with vitamin $\mathrm{D}$ and dexamethasone, and then examined for the expression of ER $\alpha$ and AR using immunohistochemical staining. Increased expression of ER $\alpha$-PA (RR: 1.1 ; CC: 0.61 to $1.99 ; \mathrm{p}=752$ ) and ARCPA (RR: 1.62; CI: 0.87-3, $\mathrm{p}=0.13$ ) determined that vitamin $\mathrm{D}$ and dexamethasone stimulated osteoblasts showed increased receptor expression than those from healthy controls (non-periodontitis). Stimulation using vitamin D and dexamethasone increased the expression of $\mathrm{ER} \alpha$, and $\mathrm{AR}$ in the osteoblasts.
\end{abstract}

Keywords: aggressive periodontitis, vitamin D and dexamethasone, osteoblasts, estrogen receptor $\alpha$, androgen receptor

\section{Introduction}

The estrogenic and androgenic hormones play a vital role in the bone homoeostasis system of the human body, including the upper and lower alveola of the maxilla and mandible. Estrogen, as mediated by the estrogen receptor- $\alpha$ $(\mathrm{ER} \alpha)$, has a primary function in the bone turn-over process and the maintenance of bone mass [1] The androgenic hormone regulates osteoclastogenesis through the androgenic receptor (AR) [2]. Estrogen and growth factor hormone function through a receptor inside the osteoblast [3]. Estrogen affects bone tissue by binding the ERs located in the cytosol and the nucleus of the osteoblasts and osteoclasts $[1,4]$. The association between bone resorption, bone mineral density (BMD) and estrogen level is modulated by the ER $\alpha$ [4].

Bone homeostasis regulator hormones are not only essential but also depend on stimulation of estrogen performance. Enjuanes et al. (2005) used vitamin D and dexamethasone to stimulate an osteoblast cell culture from healthy bone fragments, obtaining good results in terms of osteoblast replication [5]. Their 
results showed that vitamin $\mathrm{D}$ and dexamethasone played a significant role as potential stimulators of CYP19 aromatase transcription.5 In addition to its antiinflammatory properties, dexamethasone also has the capacity to function as an immunosuppressant agent in vivo [6].

Rapid tooth attachment loss is a feature of aggressive periodontitis. Clinically, aggressive periodontitis is identified by the rate and severity of bone loss even when appropriate treatment has been given. Severe attachment loss is identified by several signs: a probing depth that is more than $7 \mathrm{~mm}$, critical bone loss with furcation involvement, or radiographically, a bone loss of more than $50 \%$ occurring at an early age $[3,7]$ The bone loss pattern is usually angular and vertical on the first molar and first incisor, but the causes of localized bone loss remain unknown [8]. Aggressive periodontitis is differentiated from chronic periodontitis primarily due to 1) the rapidity of bone loss; 2) less plaque and calculus accumulation; 3) a history of aggressive periodontitis among family members, which supports the theory of genetic factors [9]. With aggressive periodontitis, rapid bone loss will occur regardless of the fact that there are minimal local factors. Typically, there is severe periodontal ligament and bone attachment loss (about $50 \%$ of single rooted teeth), the patient is less than 35 years old, they have a history of progressive periodontitis even when appropriate treatment has been given, and there are systemic diseases factors, such as a family history of diabetes with sudden and early tooth loss [3]. For these reasons, it is important to investigate whether stimulation by vitamin $\mathrm{D}$ and dexamethasone of aggressive periodontitis osteoblast cells can increase $\mathrm{ER} \alpha$ and AR.

\section{Material and Methods}

The research protocols were approved by the ethical committee of the Faculty of Dentistry Universitas Gadjah Mada (KE/FK/594/EC). Osteoblasts from aggressive periodontitis bone (AP) and from healthy bone tissue (NP) were obtained from patients who were undergoing bone grafting procedures or else odontectomy. Panoramic radiography was conducted to measure the alveolar bone loss level.

Subject criteria. The selection of patients started in August 2008 and continued until April 2010 with eight patients assigned to the AP group, with ages ranging from 20 to 35 years old. Inclusion criteria for the AP group were 1) bone loss could be determined by panoramic radiography; 2) a diagnosis of aggressive periodontitis (Fig 1a). The exclusion criteria for the AP group were systemic diseases related to the periodontitis and a smoking habit. Subjects for the NP group were patients with a healthy periodontal status but an impacted lower third molar which required odontectomy (Fig 1b). The panoramic radiograph and the estrogen and androgen examinations were conducted in one controlled laboratory (Laboratorium Pramita). 

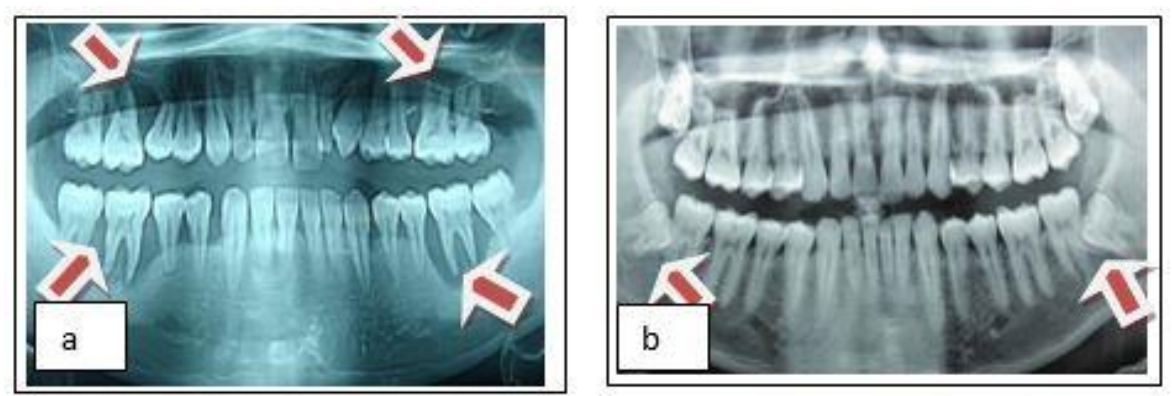

Fig 1. (a) Panoramic radiograph showed bone loss of AP subject. The arrows show the bone loss around all four first molars. (b) Panoramic radiograph of NP subject. The arrows indicate the impacted lower third molars

The bone sample collecting procedure. Bone samples from the AP subjects were obtained during open-flap surgery procedures. Bone samples from the NP group were obtained during odontectomy surgery and were retrieved from the impacted lower third molar area. A bone sample of approximately $2 \mathrm{~mm}$ was collected and put into a Petri disc and then separated from blood and other soft tissues with saline solution. The bone sample was then inserted into a microcentrifuge tube $(15 \mu \mathrm{l})$ and filled with PBS solution and penicillin-streptomycin (pen-strep) $2 \%$. All samples were stored at $4{ }^{\circ} \mathrm{C}$ in a refrigerator for a maximum of 24 hours.

Preparation of primer cell culture for AP and NP. The primer cell culture procedure was adapted from Freshney (1987) with modifications. Each bone sample was put into a petri dish, washed with $\mathrm{PBS} \pm$ two $\mathrm{mL}$, then with pen-strep (100 $\mu \mathrm{g} / \mathrm{mL}$ ). These procedures were continued until the blood and adipose tissue had vanished. The culture medium F-12, 10\% FBS was poured into the plate wells and then one $\mathrm{mL}$ pen-strep $5 \%$ and fungizone $1 \%$ were added. The bone samples were each cut into six fragments, of approximately $1 \mathrm{~mm}$ each, and then each piece was put into a plate well. The bone samples were then incubated $(\mathrm{CO} 2$, $37^{\circ} \mathrm{C}$ ) for 35 days. The cells were observed, and the medium changed every three days. Bone samples and osteoblasts were only treated in the same wells if the osteoblast, originally separated from the bone fragment, subsequently became confluent. The culture procedure was undergone in Laminar Air Flow Cabinet (LAF).

Any cells which moved out from the bone fragment and stuck to the base of the well were separated into another well and then one $\mathrm{mL}$ culture medium was added. The cells were then put into a sterile tube and centrifuged under refrigerated centrifugation $\left(4^{\circ} \mathrm{C}\right)$ at $3000 \mathrm{rpm}$ for 3 minutes, twice. The pellet that formed inside the tube was collected, seeded to the one $\mathrm{mL}$ pellet well, and then incubated at $37^{\circ} \mathrm{C}$. Cells started to grow from day seven in the AP group.

Harvesting, treatment, and seeding of osteoblast culture. After seven days, the cells were ready to be collected and stimulated. The osteoblast culture was then added with culture $1 \mathrm{~mL}$ medium (F-12, FBS $20 \%$, pen-strep $5 \%$, and fungizone $2 \%$ ). There were four treatments for each group: (a) without stimulation, (b) 
stimulated by addition of Vitamin D ( $1 \alpha, 25$-Dihydroxyvitamin D3) 10-6 mol/L5, (c) stimulated by addition of dexamethasone 10-7 mol/L5, and (d) stimulated by addition of vitamin D 10-6 mol/L and dexamethasone 10-7 mol/L. All samples were then incubated in the $\mathrm{CO} 2$ incubator for one week. The cell cultures were observed under an inverted microscope and then an immunohistochemistry stain was performed for ER $\alpha$ and AR.

Immunohistochemistry staining process. Paraffin was removed from bone samples by soaking with xylene. After gradual dehydration with alcohol, the samples were blocked with Biocare's Peroxidized I for five minutes, and then incubated with Trekkie Link for 20 minutes. The primer antibody was added: ER $\alpha$ coloring agent with phosphate buffer (Ph. 6). This was then incubated with TrekAvidinHRP Label for 10 minutes and then with Biocare's DAB substrates for 5 minutes. Then specimen was then washed with aquadest, continuing with Solution Tacha's Bluing dripping for 1 minute. The specimen was observed under the light microscope to count the number of cells.

Osteoblast cell count and observation. Osteoblasts, on the deck glass, were counted on the counter tally using a contrast phase microscope (Nikon, type eclipse E600W). The mean of the osteoblast cell count was obtained from a view of 20 fields (Nikon, type Eclipse TE2000-U). Six wells, being those with the most growth, were taken from each treatment group. Estrogen receptor $\alpha$ and AR were observed through deck glass, and represented by the four best deck glasses. The observation was performed by dividing the vision into 20 fields, the data were provided as average or mean data.

\section{Results and Discussion}

Positive osteoblasts had a brown color; in contrast, negative osteoblasts had no color. Negative osteoblasts did not contain either ER $\alpha$ or AR. This observation was conducted under the contrast phase microscope. The culture sample of ER $\mathrm{ER} \alpha$-AP on the deck glass is shown in Fig 2, and a culture sample of AR-AP, also on the deck glass, is shown in Fig 3. The expression of ER $\alpha$ and AR in a sample of the osteoblasts from the NP group is demonstrated in Fig 4. 


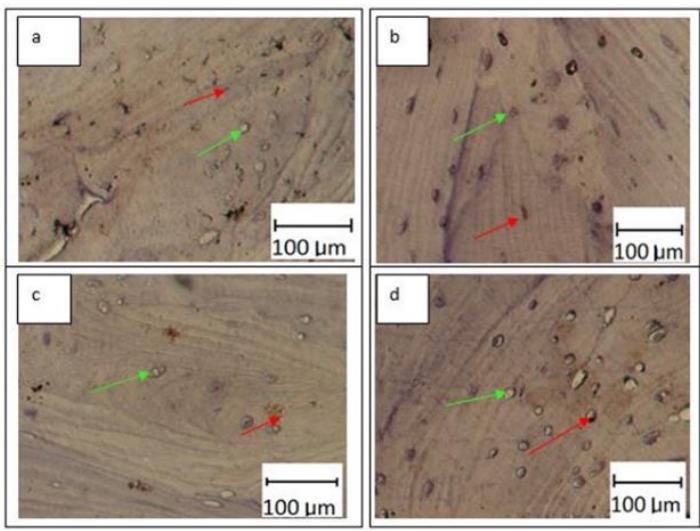

Fig 2. Expression of ER $\alpha$-AP; a) without stimulation, b) stimulated with vitamin D, c) stimulated with dexamethasone, d) stimulated with vitamin $D$ and dexamethasone
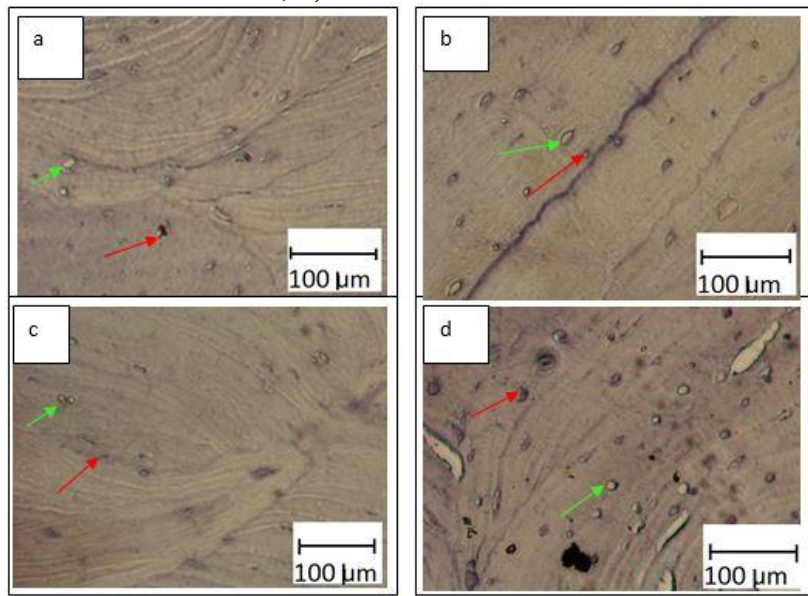

Fig 3. AR expressed of AP group a) without stimulation, b) stimulated with vitamin $D$, c) stimulated with dexamethasone, d) stimulated with vitamin $D$ and dexamethasone.
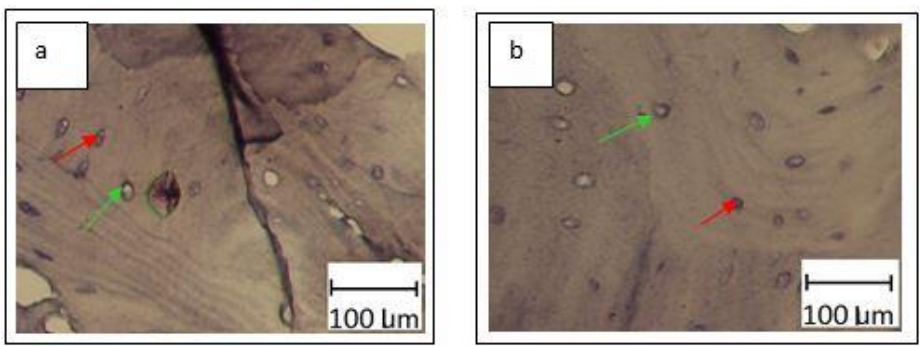

Fig 4. Control from NP groups a) osteoblast expressed ERa, b) osteoblast expressed AR 
The control group (NP group) alveolar bone samples that were collected from patients undergoing odontectomy with no sign of inflammation, were divided into two groups: NP-ER $\alpha$ and NP-AR. The mean of the NP groups' osteoblast cell number was counted (Table 1) and compared with that of the PA group. The changes that occurred after stimulation by vitamin $\mathrm{D}$ and dexamethasone in the AP and NP groups were compared.

Table 1. Mean of osteoblast cell count

\begin{tabular}{|l|c|c|}
\hline \multirow{2}{*}{ Osteoblast } & \multicolumn{3}{|c|}{ Culture and alveolar bone of non-periodontitis } \\
\cline { 2 - 3 } & ER $\boldsymbol{\alpha}-\mathbf{N P}(\mathbf{n}=\mathbf{2 0})$ & AR-NP $(\mathbf{n}=\mathbf{2 0})$ \\
\hline \multirow{2}{*}{ Mean \pm SD } & $75,55 \pm 31,75$ & $97,55 \pm 69,00$ \\
\hline
\end{tabular}

The mean of the osteoblast cell count was statistically transformed into constant 1 . The actual number of cells counted in the PA group was compared with the value of the constant from the NP group. Measurement of the effect of treatment, which was the ER $\alpha$ and AR expression data, was performed using Risk Ratio (RR).

The combination of vitamin D and dexamethasone increased the expression of $\mathrm{ER} \alpha 1.1$ times compared to that of $\mathrm{ER} \alpha-\mathrm{NP}$, and also increased the expression of AR-AP 1.62 times compared to AR-NP. Bone homeostasis happened simultaneously. Consequently, all of the bone parts, including YP19-AP, ER $\alpha$-AP, and AR$\mathrm{AP}$, increased. Vitamin D stimulation and vitamin D plus dexamethasone stimulation increased the expression of ER $\alpha$-AP and AR-AP, while dexamethasone alone increased only the AR-AP.

Table 2. Risk ratio (RR) of ERo and AR of osteoblast stimulated by vitamin D, dexamethasone, and both combined to unstimulated AP group

\begin{tabular}{|c|c|c|c|c|}
\hline \multirow{2}{*}{$\begin{array}{l}\text { Osteoblast cul- } \\
\text { ture }\end{array}$} & \multirow{2}{*}{$\begin{array}{c}\text { Unstimulated } \\
\text { AP (negative } \\
\text { control) }\end{array}$} & \multicolumn{3}{|c|}{ Stimulated } \\
\hline & & Vit D & $\begin{array}{l}\text { Dexame- } \\
\text { thasone }\end{array}$ & $\begin{array}{l}\text { Vit D+Dexa } \\
\text { methasone }\end{array}$ \\
\hline $\mathrm{ER} \alpha-\mathrm{AP}$ & $1 *$ & 1.22 & 0.89 & 1.22 \\
\hline CI & & $0.65-2.29$ & $0.43-1.83$ & $0.65-2.29$ \\
\hline $\mathrm{P}$ & 0.05 & 0.530 & 0.750 & 0.530 \\
\hline AR-AP & $1 *$ & 1.29 & 1.57 & 1.86 \\
\hline CI & & $0.60-2.77$ & $0.77-3.22$ & $0.94-3.66$ \\
\hline $\mathrm{P}$ & 0.05 & 0.52 & 0.25 & 0.07 \\
\hline
\end{tabular}

Table 2 shows the risk ratio, which describes the strength of the stimulation by vitamin D combined with dexamethasone, and by vitamin D and dexamethasone alone, as compared to the AP group with no treatment. 
Vitamin D increased ER $\alpha$-AP (1.22 times) and AR-AP (1.29 times) compared to the unstimulated AP. Dexamethasone alone also increased AR-AP expression about 1.57 times compared to the unstimulated AP. It was observed that the combination of both agents could increase AR-PA expression approximately 1.86 times.

\section{Discussion}

The greatest effect of aggressive periodontitis is rapid alveolar bone loss at a young age, which ranges from 25 to 35 years old, and occurs even when the regulation of hormones, including estrogen and androgen, remains healthy and stable. Enjuanes et al. (2005) added vitamin D and dexamethasone to an osteoblast cell culture from post-traumatic bone fragments [5]. Together with the local surgical and nonsurgical therapies, it was found that the host's condition could be enhanced through stimulation of the osteoblasts. The addition of vitamin D and dexamethasone caused stimulation of ER $\alpha$ and AR. Post the initial phase therapy, it is essential not only to obtain a bacterial free condition but also to prepare the osteoblasts to receive regenerative periodontal treatment, such as a bone graft. Osteoblast stimulation that increases ER $\alpha$ and AR should be performed to increase the patient's chance of successful periodontal therapy.

Alveolar bone is one of the organs that has active metabolism, including a mineral and organic phase. During the mineral phase, the frame of the structure is built; then during the organic phase the frame is filled continuously to create the structure of alveolar bone. As one of the dynamic organs, osteoblasts play a critical role in bone remodeling, including organic matrix synthesis and mineralization of the bone [14]. Homeostasis of bone tissue is essential in order to maintain a normal remodeling process. Estrogen and androgen hormones should be reckoned as two of the factors that can assist in osteoblast activity and regulation.

\section{Conclusion}

Vitamin D and dexamethasone increase the expression of ER $\alpha$ and AR in aggressive periodontitis osteoblasts.

\section{References}

1. Gennari L, Merlotti D, De Paola V, Calabro A, Becherini L, Martini G, Nuti R. Estrogen receptor gene polymorphisms and the genetics of osteoporosis: a HuGE review. American journal of epidemiology. 2005 Feb 15;161(4):307-20.

2. Vanderschueren D and Vandenput, L. Androgens and osteoporosis. Andrologies, 2000, 32:125-130.

3. Kornman KS, Wilson TG. Making a clinical diagnosis and treatment plan. In: Fundamentals of Periodontics, 2nd ed., Chicago: Quintessence Publishing Co, Inc, 2003, 312, 323.

4. Khosla S, Riggs BL, Atkinson EJ, Oberg AL, Mavilia C, Del Monte F, Melton III LJ, Brandi ML. Relationship of estrogen receptor genotypes to bone mineral density and to rates of bone loss in men. J Clin Endocrinol Metabol. 2004;89(4):1808-16. 
5. Enjuanes A, Garcia-Giralt N, Supervía A, Nogués X, Ruiz-Gaspà S, Bustamante M, Mellibovsky L, Grinberg D, Balcells S, Díez-Pérez A. Functional analysis of the I. 3, I. 6, pII and I. 4 promoters of CYP19 (aromatase) gene in human osteoblasts and their role in vitamin D and dexamethasone stimulation. Eur J Endocrinol. 2005;153(6):981-8.

6. Mostafa NZ, Uludağ H, Varkey M, Dederich DN, Doschak MR, El-Bialy TH. In vitro osteogenic induction of human gingival fibroblasts for bone regeneration. Open Dent J. $2011 ; 5: 139$.

7. Seiler JS, Herold RW. The use of systemic antibiotics in the treatment of aggressive periodontal disease. General Dent. 2005;53(2):155-9.

8. Carranza FA, Takei H. Bone loss and pattern of bone destruction. In, Newman MG, Takey HH, Klokkevold PR, Carranza FA, Carranza's Clinical Periodontology, 10th ed., St Louis: Saunders Elsevier, 2006a, 452-466.

9. Novak MJ. Classification of diseases and condition affecting the periodontium. In, Newman MG, Takey HH, Klokkevold PR, Carranza FA, Carranza's Clinical Periodontology, 10th ed., St Louis: Saunders Elsevier, 2006, 100-109.

10. Freshney RI. Culture of Animal Cells, A Manual of Basic Technique, 2nd ed., New York: JohnWilly and Sons, Inc., 1987, 270-272.

11. Hamilton I, Statistic with STATA. Updated for Version 9, Belmont: Duxbury, Thomson Learning, 2006.

12. Harris MN, Mátyás L. The econometrics of gravity models. Melbourne Institute of Applied Economic and Social Research; 1998 Feb.

13. Anon. Manual STATA 11, Stata Press Publication, College Station, Texas, 2009.

14. Schwartz ZV, Goultschin J, Dean DD, Boyan BD. Mechanisms of alveolar bone destruction in periodontitis. Periodontology 2000. 1997;14(1):158-72. 